\title{
Atividade antimicrobiana in vitro de uma combinação de óleos vegetais de caju e mamona e de óleos essenciais de cravo, eugenol, timol e vanilina contra bactérias Gram-negativas e Gram-positivas no rúmen de bovinos
}

In vitro antimicrobial activity of a blend of cashew and castor vegetable oils and clove, eugenol, thymol, and vanillin essential oils against Gram-negative and Gram-positive ruminal bacteria Actividad antimicrobiana in vitro de una mezcla de aceites vegetales de anacardo y ricino y aceites esenciales de clavo, eugenol, timol y vainillina contra bacterias ruminales Gram negativas y Gram positivas

Aylle Medeiros Matos ORCID: https://orcid.org/0000-0002-3219-0238 Universidade Estadual de Maringá, Brasil E-mail: ayllemedeiros@hotmail.com

Mariana Garcia Ornaghi ORCID: https://orcid.org/0000-0003-1440-5861 Safeeds Nutrição Animal, Brasil E-mail: marianaornaghi@hotmail.com

Venício Macêdo Carvalho ORCID: https://orcid.org/0000-0002-2875-7799 Universidade Estadual de Maringá, Brasil E-mail: venicio_@hotmail.com

Vicente Alfonso Diaz Avila ORCID: https://orcid.org/0000-0003-2550-2392 Universidade Estadual de Maringá, Brasil E-mail: vadiaza@ut.edu.co Edinéia Bonin

ORCID: https://orcid.org/0000-0002-0242-1170 Universidade Estadual de Maringá, Brasil E-mail: bonin_in@hotmail.com

Ricardo de Araújo Castilho ORCID: https://orcid.org/0000-0002-7724-6215

Safeeds Nutrição Animal, Brasil

E-mail: ricardo@safeeds.com.br

Anderson Valdiney Gomes Ramos ORCID: https://orcid.org/0000-0001-9863-018X

Universidade Estadual de Maringá, Brasil

E-mail: anderson_ramos.19@hotmail.com

Debora Cristina Baldoqui ORCID: https://orcid.org/0000-0002-5824-8573 Universidade Estadual de Maringá, Brasil E-mail: dcbaldoqui@gmail.com

Rodolpho Martin do Prado ORCID: https://orcid.org/0000-0003-3529-7783 Universidade Estadual de Maringá, Brasil E-mail: rodolphoprado@hotmail.com

Ivanor Nunes do Prado

ORCID: https://orcid.org/0000-0003-1058-7020 Universidade Estadual de Maringá, Brasil E-mail: inprado@uem.br

\section{Resumo}

A preocupação pública com o uso rotineiro de antibióticos e ionóforos na dieta de ruminantes aumentou devido ao surgimento de bactérias resistentes aos antibióticos que podem representar riscos à saúde humana. Assim, esforços têm sido empregados para o desenvolvimento de compostos alternativos para substituir antibióticos e ionóforos na dieta de ruminantes. Este estudo foi realizado para avaliar os efeitos in vitro de uma mistura contendo óleos vegetais de caju e mamona e óleos essenciais de cravo-da-índia, eugenol, timol e vanilina sobre a atividade das bactérias Gram-negativas 
e Gram-positivas presentes no rúmen. O experimento foi elaborado de forma que cada bactéria fosse exposta às doses de $1,5,3,5$ e $6,0 \mathrm{mg} / \mathrm{mL}$ da mistura, com seis repetições. As bactérias foram cultivadas em meio M2 de Hobson em tubos Hungate. A atividade antimicrobiana foi avaliada em espectrofotômetro a $600 \mathrm{~nm}$. As leituras foram realizadas 0 , 8, 12 e 24 horas após a inoculação a $39^{\circ} \mathrm{C}$. As quatro concentrações $(1,5,3,0,4,5$ e 6,0 mg/mL) da mistura de óleos vegetais e essenciais inibiram o crescimento da Prevotella albensis, Prevotella bryantii, Prevotella ruminicola e Anaerovibrio lipolyticus 8 e 12 horas após a incubação. Para Ruminococcus albus e Ruminococcus flavefaciens a adição da mistura de óleos essenciais nas concentrações de 3,0 e 4,5 mg/mL resultou em maior impacto na dinâmica de crescimento, com redução na densidade óptica após 12 h de incubação. Em conclusão, os resultados mostram que a ação combinada dos óleos vegetais e essenciais influencia o crescimento de bactérias gram-negativas e gram-positivas e pode ser usado como um modulador ruminal. Deste modo, o estudo contribui com novas informações sobre a ação combinada dos óleos vegetais e essenciais como agentes antimicrobianos na produção de ruminantes.

Palavras-chave: Compostos encapsulados; Inibição do crescimento; Aditivos naturais; Ambiente ruminal; Modulação ruminal.

\begin{abstract}
Public concern over the routine use of antibiotics and ionophores in ruminant diets has increased due to the emergence of antibiotic-resistant bacteria that may represent risks to human health. Thus, efforts have been employed toward the development of alternative compounds to replace antibiotics and ionophores in ruminants' diets. This study was carried out to investigate the in vitro effects of a blend containing cashew and castor vegetable oils and clove, eugenol, thymol, and vanillin essential oils on the activity of Gram-negative and Gram-positive ruminal bacteria. The experiments were designed so that each bacterium would be exposed to doses of $1.5,3.0,4.5$, and $6.0 \mathrm{mg} / \mathrm{mL}$ of the blend, with six replicates. Bacteria were cultivated on Hobson's M2 medium in Hungate tubes. Antimicrobial activity was evaluated using a spectrophotometer at $600 \mathrm{~nm}$. Readings were performed $0,8,12$, and 24 hours after inoculation at $39^{\circ} \mathrm{C}$. The four $(1.5,3.0,4.5$, and $6.0 \mathrm{mg} / \mathrm{mL})$ concentrations of the blend of vegetable and essential oils inhibited the growth of Prevotella albensis, Prevotella bryantii, Prevotella ruminicola, and Anaerovibrio lipolyticus at 8 and 12 hours after the incubation. For Ruminococcus albus and Ruminococcus flavefaciens the addition of the blend of EO of concentrations of 3.0 and $4.5 \mathrm{mg} / \mathrm{mL}$ resulted in a greater impact on growth dynamics, with a reduction in optical density after $12 \mathrm{~h}$ of incubation. The findings of this research establish the combined action of the vegetable and essential oils was found to influence the growth of gram-negative and gram-positive bacteria and can be used as a rumen modulator. The study contributes to new information about the combined action of the vegetable and essential oils as antimicrobial agents on ruminant production.
\end{abstract}

Keywords: Encapsulate compounds; Growth inhibition; Natural additives; Rumen environment; Ruminal modulation.

\title{
Resumen
}

La preocupación pública por el uso rutinario de antibióticos e ionóforos en las dietas de rumiantes ha aumentado debido a la aparición de bacterias resistentes a los antibióticos que pueden representar riesgos para la salud humana. Por lo tanto, se han realizado esfuerzos para el desarrollo de compuestos alternativos para reemplazar los antibióticos y los ionóforos en la dieta de los rumiantes. Este estudio se llevó a cabo para investigar los efectos in vitro de una mezcla que contiene aceites vegetales de anacardo y ricino y aceites esenciales de clavo, eugenol, timol y vainillina sobre la actividad de bacterias ruminales Gram negativas y Gram positivas. Los experimentos se diseñaron para que cada bacteria fuera expuesta a dosis de $1.5,3.0,4.5$ y $6.0 \mathrm{mg} / \mathrm{mL}$ de la mezcla, con seis repeticiones. Las bacterias se cultivaron en el medio M2 de Hobson en tubos Hungate. La actividad antimicrobiana se evaluó usando un espectrofotómetro a $600 \mathrm{~nm}$. Las lecturas se realizaron $0,8,12$ y 24 horas después de la inoculación a $39^{\circ} \mathrm{C}$. Las cuatro concentraciones $(1,5,3,0,4,5$ y $6,0 \mathrm{mg} / \mathrm{mL})$ de la mezcla de aceites vegetales y esenciales inhibieron el crecimiento de Prevotella albensis, Prevotella bryantii, Prevotella ruminicola y Anaerovibrio lipolyticus a las 8 y 12 horas después de la incubación. Para Ruminococcus albus y Ruminococcus flavefaciens la adición de la mezcla de EO de concentraciones de 3.0 y $4.5 \mathrm{mg} / \mathrm{mL}$ resultó en un mayor impacto en la dinámica de crecimiento, con una reducción de la densidad óptica luego de 12 h de incubación. Los hallazgos de esta investigación establecen que la acción combinada de los aceites vegetales y esenciales influye en el crecimiento de bacterias gramnegativas y grampositivas y puede utilizarse como modulador del rumen. El estudio aporta nueva información sobre la acción combinada de los aceites vegetales y esenciales como agentes antimicrobianos en la producción de rumiantes.

Palabras clave: Encapsular compuestos; Inhibición del crecimiento; Aditivos naturales; Ambiente ruminal; Modulación ruminal.

\section{Introdução}

Antibióticos, ionóforos e leveduras, entre outros compostos, são comumente adicionados às dietas de ruminantes em muitos países para prevenir doenças e distúrbios metabólicos, bem como para melhorar o desempenho animal e a eficiência alimentar (Fugita et al., 2018; Ornaghi et al., 2017; Souza et al., 2019), modulação ruminal (Benchaar et al., 2008) e qualidade 
da carne (Monteschio et al., 2019; Rivaroli et al., 2016; Souza et al., 2019). Assim, as perdas de energia pela eructação do gás metano são reduzidas e a razão acetato: propionato é melhorada (Russell \& Strobel, 1989). No entanto, a preocupação pública com o uso rotineiro de antibióticos e ionóforos na dieta de ruminantes aumentou devido ao surgimento de bactérias mais resistentes a antibióticos que podem representar riscos à saúde humana (Schäberle \& Hack, 2014). Assim, esforços têm sido empregados para o desenvolvimento de compostos alternativos para substituir antibióticos e ionóforos na dieta de ruminantes. Extratos de plantas e óleos essenciais e vegetais oferecem uma oportunidade a esse respeito (Cruz et al., 2014; Fugita et al., 2018; Rivaroli et al., 2016; Souza et al., 2019) visto que muitas plantas produzem metabólitos secundários com atividades antimicrobianas e propriedades antioxidantes (Jayasena \& Jo, 2013; Patra \& Saxena, 2010).

A atividade antimicrobiana de extratos vegetais tem sido atribuída a vários compostos fenólicos, como carvacrol, eugenol, timol e vanilina (Burt, 2004), bem como cardol, cardanol, ácidos anacárdico e ricinoléico (Zotti et al., 2017). Assim, eles agem como agentes fenólicos, perturbando a força de prótons, o fluxo de elétrons, o transporte ativo e a coagulação do conteúdo celular (Burt, 2004; Dorman \& Deans, 2000). Os ácidos fenólicos exercem efeitos antimicrobianos por meio da difusão do ácido não associado através da membrana, levando à acidificação do citoplasma e, em alguns casos, à morte celular (GuilGuerrero et al., 2016). No entanto, fatores relacionados ao meio lipofílico como pH, substituições de anéis (grupos hidroxila e metoxi) e a saturação da cadeia lateral são determinantes da atividade dos ácidos cianâmicos (Burt, 2004; Patra \& Saxena, 2009). Em geral, os compostos de extratos vegetais são bastante ativos contra a atividade de bactérias do rúmen, embora alguns autores tenham observado baixa eficiência no caso de compostos individuais (Saavedra et al., 2010). Os efeitos aditivos, antagônicos e sinérgicos das misturas de extratos de plantas foram descritos como mais ativos do que os extratos individuais (Burt, 2004; Valero et al., 2016). Foi demonstrado que estes compostos na forma pura exibem atividade antioxidante (Kempinski et al., 2017; Monteschio et al., 2017; Vital et al., 2018), antifúngica (Zuzarte et al., 2013), antibacteriana (Deans \& Ritchie, 1987) e antimicrobiana (Hammer et al., 1999).

As bactérias Gram-negativas possuem uma membrana externa que lhes confere uma superfície hidrofílica, devido à presença de moléculas de lipopolissacarídeos (Nikaido, 2003). No entanto, pequenos solutos hidrofílicos podem passar através da membrana externa por meio de proteínas porinas (Nikaido, 2003). A membrana externa de bactérias gram-negativas serve como uma barreira de penetração às macromoléculas e compostos hidrofóbicos (Helander et al., 1998; Nikaido, 2003). Assim, as bactérias gram-negativas são relativamente resistentes a compostos hidrofóbicos de plantas, antibióticos ou ionóforos (Nikaido, 2003). No entanto, a membrana externa não é totalmente impermeável às moléculas hidrofóbicas, algumas das quais podem atravessar lentamente as porinas (Helander et al., 1998; Nikaido, 2003). Em geral, contornar a membrana externa é um pré-requisito para que os solutos exerçam atividade contra bactérias gram-negativas e gram-positivas na modulação ruminal. Portanto, poderia ser interessante a avaliação de compostos antibacterianos presentes em plantas e os óleos essenciais quanto à sua atividade contra bactérias gram-negativas na fermentação ruminal. Acredita-se que a maioria dos extratos vegetais exerça sua atividade antimicrobiana ao interagir com processos associados à membrana celular bacteriana, incluindo transporte de elétrons, gradientes de íons, translocação de proteínas, fosforilação e outras reações dependentes de enzimas (Dorman \& Deans, 2000). Helander et al. (1998) observaram que o timol e o carvacrol rompem a membrana celular, diminuindo assim o pool de ATP intracelular e aumentando o pool de ATP extracelular de Escherichia coli. Por outro lado, várias teorias foram propostas para explicar o mecanismo pelo qual os extratos vegetais exercem atividade antibacteriana (Benchaar et al., 2008; Guil-Guerrero et al., 2016; Olagaray \& Bradford, 2019; Patra \& Saxena, 2010). Os extratos de plantas compreendem um grande número de componentes, portanto, é mais provável que sua atividade antibacteriana não seja devida a um modo de ação específico, mas envolva vários alvos na célula bacteriana (Burt, 2004).

Estudos anteriores concentraram-se nos compostos isolados de cada planta (Guerrero et al., 2018; Ornaghi et al., 2017; Sary et al., 2019) ou, em alguns casos, em misturas de metabólitos secundários de plantas (Cruz et al., 2014; Fugita et al., 2018; 
Monteschio et al., 2017, 2019; Souza et al., 2019). O uso de uma mistura de metabólitos secundários pode potencializar o sinergismo dos compostos finais. Em alguns estudos, vários óleos vegetais e essenciais e extratos de plantas foram combinados para aumentar a atividade antioxidante e antimicrobiana e para melhorar o desempenho animal e a vida útil de carnes e produtos cárneos devido ao efeito sinérgico (Fugita et al., 2018; Kempinski et al., 2017; Monteschio et al., 2017; Vital et al., 2018). Com esse efeito, maior poder antioxidante pode ser obtido quando mais compostos essenciais são usados em conjunto do que com o uso exclusivo de um composto vegetal individual (Hyldgaard et al., 2012).

Assim, este estudo foi realizado com o objetivo de investigar os efeitos in vitro de uma mistura contendo óleos vegetais de caju e mamona e óleos essenciais de cravo, eugenol, timol e vanilina sobre a atividade de bactérias ruminais Gram-negativas e Gram-positivas.

\section{Metodologia}

\subsection{Comitê de ética e local}

Este experimento foi aprovado pelo Departamento de Produção Animal e pelo Comitê de Ética em Pesquisa da Universidade Estadual de Maringá e obedeceu aos princípios norteadores da pesquisa biomédica com animais nº. 081/2014. Este trabalho é uma pesquisa quantitativa (Pereira et al., 2018), e foi realizado no Laboratório de Microbiologia da Universidade Estadual de Maringá, Paraná, Brasil.

\subsection{Preparação de mistura de óleos vegetais e essenciais}

O óleo essencial de cravo-da-índia (Syzygium aromaticum) foi obtido da FERQUIMA ${ }^{\circledR}$ (Vargem Grande Paulista, São Paulo, Brasil). Os óleos vegetais de caju (Anacardium occidentale) e mamona (Ricinus communis), bem como o composto micro encapsulado (eugenol, timol e vanilina) foram obtidos da SAFEEDS ${ }^{\circledR}$ (Cascavel, Paraná, Brasil). A mistura foi diluída e homogeneizada em doses de 1,5, 3,0, 4,5 e 6,0 mg/mL em solução de Tween ${ }^{\circledR} 80(5 \%)$ e agitada por 15 minutos. O processo foi repetido três vezes em intervalos de 15 minutos para diluição completa. As soluções foram armazenadas em frascos fechados e mantidos à temperatura de $4^{\circ} \mathrm{C}$.

\subsection{Extração de moléculas bioativas}

As moléculas bioativas da mistura de óleos vegetais e essenciais $(50 \mathrm{~g})$ foram extraídas com metanol/água $(1: 1,50 \mathrm{~mL}$, v/v). Após a mistura da amostra, esta foi sucessivamente particionada com n-hexano e acetato de etila. O sobrenadante foi recuperado para análise do perfil fitoquímico. Para as análises dos compostos bioativos e da atividade antioxidante, o sobrenadante foi recuperado e diluído em metanol (1:200, v/v). A atividade antioxidante foi avaliada usando ensaios de 2,2 endifenil-1-picrilhidrazil (DPPH), 2,2'-azino-bis (ácido 3-etilbenztiazolina-6-sulfônico) (ABTS) e poder antioxidante redutor férrico (FRAP).

\subsection{Compostos bioativos e capacidade antioxidante}

\subsubsection{Perfil fito químico}

A composição da mistura de óleos vegetais e essenciais foi determinada por ressonância magnética nuclear (RMN). O espectro 13C-NMR foi registrado em um espectrômetro Bruker Avance III HD (Bruker ${ }^{\circledR}$, EUA) operando a 75,5 MHz, usando DMSO-d6 (Sigma-Aldrich) como solvente. Os compostos foram identificados pelos índices de alterações químicas da unidade $\delta(\mathrm{ppm})$ e por comparação com dados relatados na literatura (Figura 1). 
Figure 1. Perfil da mistura de óleos vegetais de caju e mamona e óleos essenciais de cravo, eugenol, vanilina, timol, usando ${ }^{13} \mathrm{C}$ NMR espectro (DMSO-d6, 75.5 MHz).
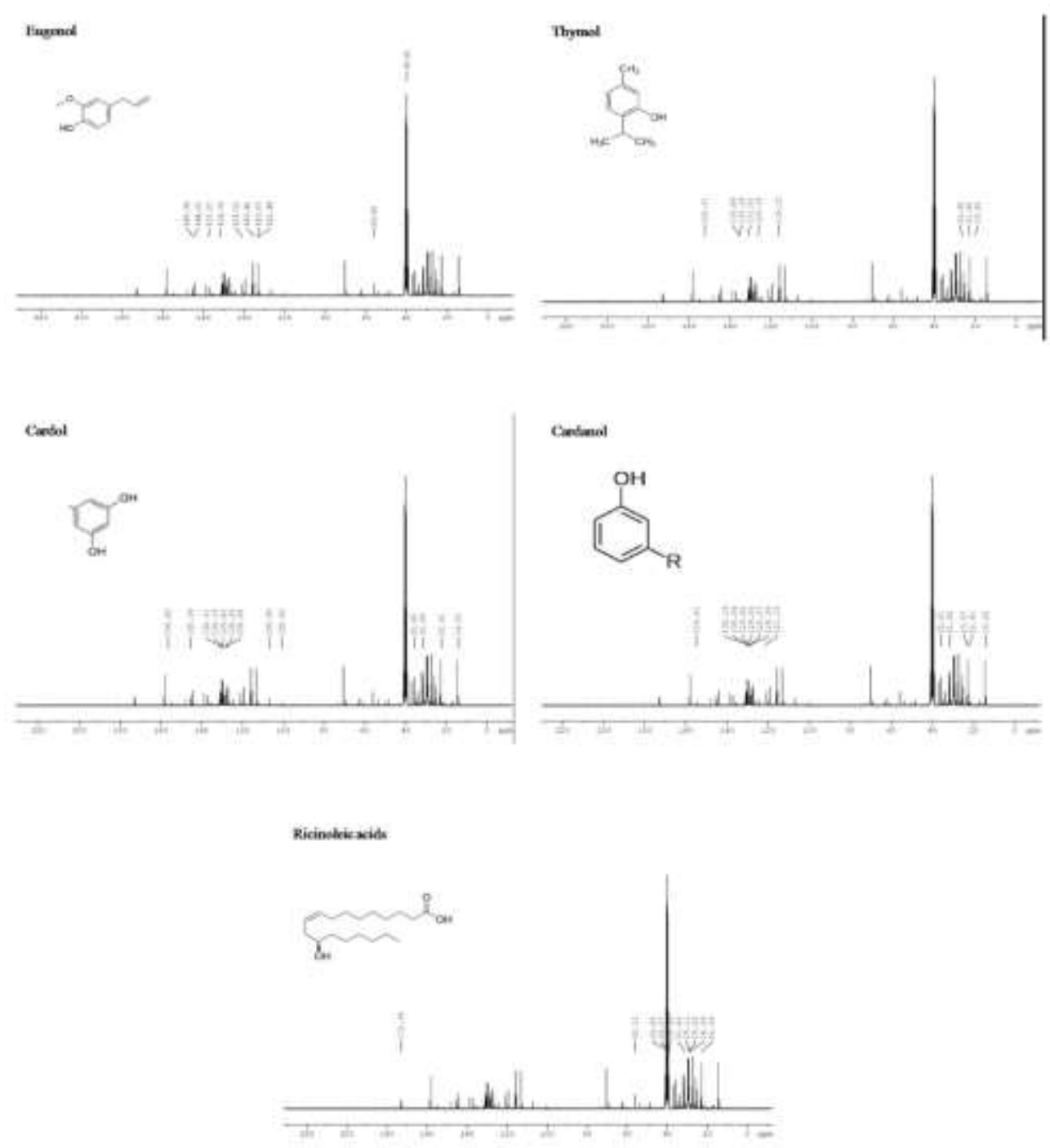

Fonte: Autores.

\subsubsection{Conteúdo total de polifenóis (TPC)}

O extrato $(125 \mu \mathrm{L})$ foi misturado com $125 \mu \mathrm{L}$ de reagente Folin-Ciocalteu (1:1 água deionizada) e $2.250 \mu \mathrm{L}$ de carbonato de sódio (28 g/L) (1:1:20). As soluções foram incubadas no escuro por $30 \mathrm{~min}$. A absorbância foi medida a $725 \mathrm{~nm}$ usando um espectrofotômetro (EvolutionTM 300, Thermo Fisher Scientific, UK). Uma curva de absorbância padrão foi preparada usando 0 - $300 \mathrm{mg} / \mathrm{L}$ de ácido gálico. Os resultados foram expressos como ácido gálico equivalente (mg GAE/g amostra) (Singleton \& Rossi, 1965).

\subsubsection{Capacidade antioxidante}

\subsubsection{Ensaio de eliminação de radical ABTS}

O ensaio ABTS foi conduzido de acordo com Re et al. (1999), com algumas modificações (Vital et al., 2016). ABTS + foi formado pela interação de $7 \mathrm{mM}$ de $\operatorname{ABTS}(5 \mathrm{~mL})$ com $140 \mathrm{mM}$ de persulfato de potássio $(88 \mu \mathrm{L})$ por $16 \mathrm{~h}$ em temperatura 
ambiente no escuro. Os extratos $(40 \mu \mathrm{L})$ foram misturados com solução ABTS + $(1960 \mu \mathrm{L})$ e a absorbância foi medida após 6 min a $734 \mathrm{~nm}$. A atividade antioxidante (\%) foi calculada usando a Equação 1:

Atividade de eliminação de radical ABTS $(\%)=(1-($ Uma amostra $t /$ Uma amostra $t=0) * 100$.

Onde Asample t é a absorbância da amostra em 6 min, e Asample t = 0 é a absorbância da amostra no tempo zero.

\subsubsection{Ensaio de eliminação de radical pelo DPPH}

Para o DPPH, os extratos da amostra ( $150 \mu \mathrm{L})$ foram misturados com uma solução metanólica de DPPH (60 $\mu \mathrm{M})(2850$ HL). A absorbância foi lida a $515 \mathrm{~nm}$, após 30 min no escuro (Li et al., 2009), com algumas modificações (Vital et al., 2016). A atividade antioxidante foi calculada usando a Equação 2:

Atividade de eliminação do radical DPPH $(\%)=(1-($ Uma amostra $\mathrm{t} /$ Uma amostra $\mathrm{t}=0) * 100$.

Onde Asample t é a absorbância da amostra em 30 min, e Asample t = 0 é a absorbância da amostra no tempo zero.

\subsubsection{Poder antioxidante redutor férrico pelo FRAP}

O ensaio FRAP foi determinado de acordo com o protocolo publicado por Zhu et al. (2002). O extrato (250 $\mu \mathrm{L})$ foi misturado com 1,25 mL de tampão fosfato de sódio $50 \mathrm{mmol} / \mathrm{L} \mathrm{em} \mathrm{pH} \mathrm{7,0} \mathrm{e} \mathrm{1,25} \mathrm{mL} \mathrm{de} \mathrm{ferrecianeto} \mathrm{de} \mathrm{potássio} \mathrm{a} 1 \%$. A mistura foi homogeneizada e incubada a $50^{\circ} \mathrm{C}$ por $20 \mathrm{~min}$. Após o resfriamento, foram adicionados $1,25 \mathrm{~mL}$ de ácido tricloroacético (10\%) e a solução centrifugada por $10 \mathrm{~min}$ a $3.000 \mathrm{rpm}$. Uma alíquota do sobrenadante $(2,5 \mathrm{~mL})$ foi adicionada a $500 \mu \mathrm{L}$ de cloreto férrico $(0,1 \%)$ e a absorbância foi lida imediatamente a $700 \mathrm{~nm}$. Os resultados foram expressos em mg GAE/g de amostra.

\subsection{Preparação do meio de cultura e atividade bacteriana}

Amostras de líquido ruminal foram coletadas por meio de fístulas de três bovinos mestiços (European $\times$ Nelore) com idade de $24 \pm 2,2$ meses e peso corporal de $424 \pm 3,8 \mathrm{~kg}$. Os bovinos foram alimentados com dieta basal composta por $70 \%$ de concentrado e $30 \%$ de silagem de milho oferecida ad libitum. As amostras foram então centrifugadas $(12.000 \times \mathrm{g})$ a $4^{\circ} \mathrm{C}$ por 25 min (Beckman-Coulter High-Performance Centrifuge). O líquido sobrenadante, desprovido de qualquer material particulado, foi agitado e armazenado a $-20^{\circ} \mathrm{C}$.

A composição do meio era (por litro): líquido ruminal clarificado, $200 \mathrm{~mL}$; glicose, 2,0 g; maltose, 2,0 g; hidrogeno carbonato de sódio, 4,0 g; bacto-casítono, 10,0 g; extrato de levedura, 2,5 g; celubiose, 2,0 g; solução mineral I, $150 \mathrm{~mL}$; solução mineral II, $150 \mathrm{~mL}$; solução de lactato de sódio, $10 \mathrm{~mL}$; solução de resarium, $1 \mathrm{~mL}$; água destilada, até $1.000 \mathrm{~mL}$ e cisteínaHCL, 1,0 g. A composição da solução mineral I foi fosfato dipotássico, 3,0 g, até $1.000 \mathrm{~mL}$ de água destilada, enquanto a solução mineral II continha: fosfato monopotássico, 3,0 g; sulfato de amônio, 6,0 g; cloreto de sódio, 6,0 g; sulfato de magnésio, 6,0 g; cloreto de cálcio, $0,6 \mathrm{~g}$, até $1.000 \mathrm{~mL}$ de água destilada. $\mathrm{O}$ pH do meio foi ajustado para 6,8 .

$\mathrm{O}$ meio foi fervido para deslocar o oxigênio dissolvido e então resfriado em gelo enquanto era saturado com um fluxo contínuo de $\mathrm{CO}_{2}$ livre de $\mathrm{O}_{2}$ por cerca de $20 \mathrm{~min}$. O meio foi fracionado em tubos de cultura anaeróbica Hungate $(9 \mathrm{~mL})$ e selado com rolhas de butil flangeadas. Os tubos selados foram imediatamente auto clavados ( 20 min a $120{ }^{\circ} \mathrm{C}$ ) e após resfriamento foram armazenados em temperatura ambiente, sem a presença de luz (Hobson, 1969; Hungate, 1966), até o momento da análise.

As cepas de bactérias gram-negativas estudadas foram: Prevotella albensis (DSM 11370), Prevotella bryantii (DSM 11371), Prevotella ruminicola (ATCC 19189 ${ }^{\mathrm{TM}}$ ), Anaerovibrio lipolyticus (DSM 3074), Treponema saccharophilum (DSM 2985) e Succinivibrio dextrinosolvens 3072). As cepas gram-positivas foram: Ruminococcus albus (DSM 20455), Ruminococcus flavefaciens (DSM 25089), Streptococcus bovis (DSM 20480) e Lachnospira multipara (DSM 3073). 
Os testes preliminares foram realizados apenas com a solução Tween ${ }^{\circledR} 80(5 \%)$, e observou-se que não produziu nenhuma zona de inibição, indicando que por si só não inibiu o crescimento de bactérias.

Para os experimentos de crescimento, a mistura dos óleos vegetais e essenciais e as bactérias foram adicionadas via seringa e cultivadas em meio 2 de Hobson (Hobson, 1969), em tubos Hungate, de acordo com os seguintes tratamentos: 1,0 mL da bactéria teste (controle ); $0,5 \mathrm{~mL}$ da mistura, a uma concentração de $1,5 \mathrm{mg} / \mathrm{mL}+0,5 \mathrm{~mL}$ da bactéria teste $(1,5 \mathrm{mg} / \mathrm{mL}$ ); 0,5 $\mathrm{mL}$ da mistura, a uma concentração de $3,0 \mathrm{mg} / \mathrm{mL}+0,5 \mathrm{~mL}$ da bactéria teste $(3,0 \mathrm{mg} / \mathrm{mL}) ; 0,5 \mathrm{~mL}$ da mistura, a uma concentração de 4,5 mg/mL + 0,5 mL da bactéria teste $(4,5 \mathrm{mg} / \mathrm{mL})$; e $0,5 \mathrm{~mL}$ da mistura, a uma concentração de $6,0 \mathrm{mg} / \mathrm{mL}$ + $0,5 \mathrm{~mL}$ da bactéria teste $(6,0 \mathrm{mg} / \mathrm{mL})$. Três tubos replicados foram usados para cada condição. As bactérias foram incubadas no escuro a uma temperatura controlada de $39^{\circ} \mathrm{C}$. O crescimento bacteriano foi avaliado medindo a densidade óptica a $600 \mathrm{~nm}$ (EvolutionTM 300, Thermo Fisher Scientific, Reino Unido) às 0, 8, 12 e 24 horas.

\subsection{Análise estatística}

Foram realizadas análises exploratórias dos dados longitudinais e observou-se que todas as variáveis de resposta (ou seja, as dez cepas bacterianas estudadas) apresentaram distribuição assimétrica positiva. Foi aplicada uma metodologia de modelo linear generalizado misto (GLMM); mais especificamente, o modelo gama com função log-link. Para isso, estes foram baseados em equações de estimação generalizadas (GEE), que são a distribuição marginal de modelos mistos, ou seja, sem a denotação de efeitos aleatórios. Nesse caso, foi incorporada a estrutura de covariância intra-unidade da amostra. O AR (1) foi considerado: especificamente, a autorregressão de primeira ordem por representar melhor a variação dos dados igualmente espaçados, bem como porque à medida que o intervalo de tempo entre duas observações em média aumentou, a covariância diminuiu, conforme recomendado por Diggle et al. (2002) (Seção 5.2). Por meio da análise dos resíduos, observou-se que os modelos utilizados podem ser considerados adequados.

Os modelos foram ajustados pelo software estatístico R usando o pacote geeglm.

$\mathrm{Y}=\beta \mathrm{o}+\beta 1$ tempo $+\beta 2$ concentração $+\beta 3$ tempo * concentração $+\varepsilon$ (erro).

Para cada $\mathrm{Y} \sim$ Gamma $($ link $=\log$ ), estrutura de correlação "AR1" em que todos os modelos foram ajustados no aplicativo R usando o pacote geeglm.

\section{Resultados}

\subsection{Compostos bioativos e capacidade antioxidante}

No espectro 13C-NMR (Figura 1) foram observados os sinais característicos de eugenol, timol, cardol, cardanol e ácidos ricinoléico na mistura de óleos vegetais e essenciais. Esse sinal está de acordo com achados anteriores da literatura.

A mistura de óleos vegetais e essenciais apresentou teor de polifenóis totais de 188,45 mg GAE/g. Em relação à atividade antioxidante, a análise do poder redutor do ferro apresentou valor de 4,22 $\mathrm{mg}$ GAE/g percentuais de eliminação de radicais livres de 12,75 e 10,71\% de DPPH e ABTS, respectivamente.

\subsection{Atividade antibacteriana}

Os tempos de incubação das bactérias neste estudo foram 0, 8, 12 e 24 horas. O tempo de passagem da digestão pelo compartimento retículo-ruminal de bovinos alimentados com dietas ricas em grãos varia de 6 a $8 \%$ por hora. Assim, nas primeiras 12 horas, 70 a $90 \%$ da digestão deixa o compartimento retículo-rúmen. Portanto, o tempo de 24 horas foi incluído apenas do ponto de vista didático. 


\subsubsection{Bactéria Gram-negativa}

A atividade antibacteriana (crescimento), medida pela densidade óptica, aumentou linearmente ( $\mathrm{P}<0,001)$ no tratamento controle ao longo do tempo de incubação (de 0 a 12 horas) para as seis bactérias gram-negativas estudadas (Figura 2).

Figura 2. Evolução da atividade das bactérias Gram-negativas na mistura de óleos vegetais de caju e mamona e óleos essenciais de cravo, eugenol, timol e vanilina durante 24 horas de incubação.
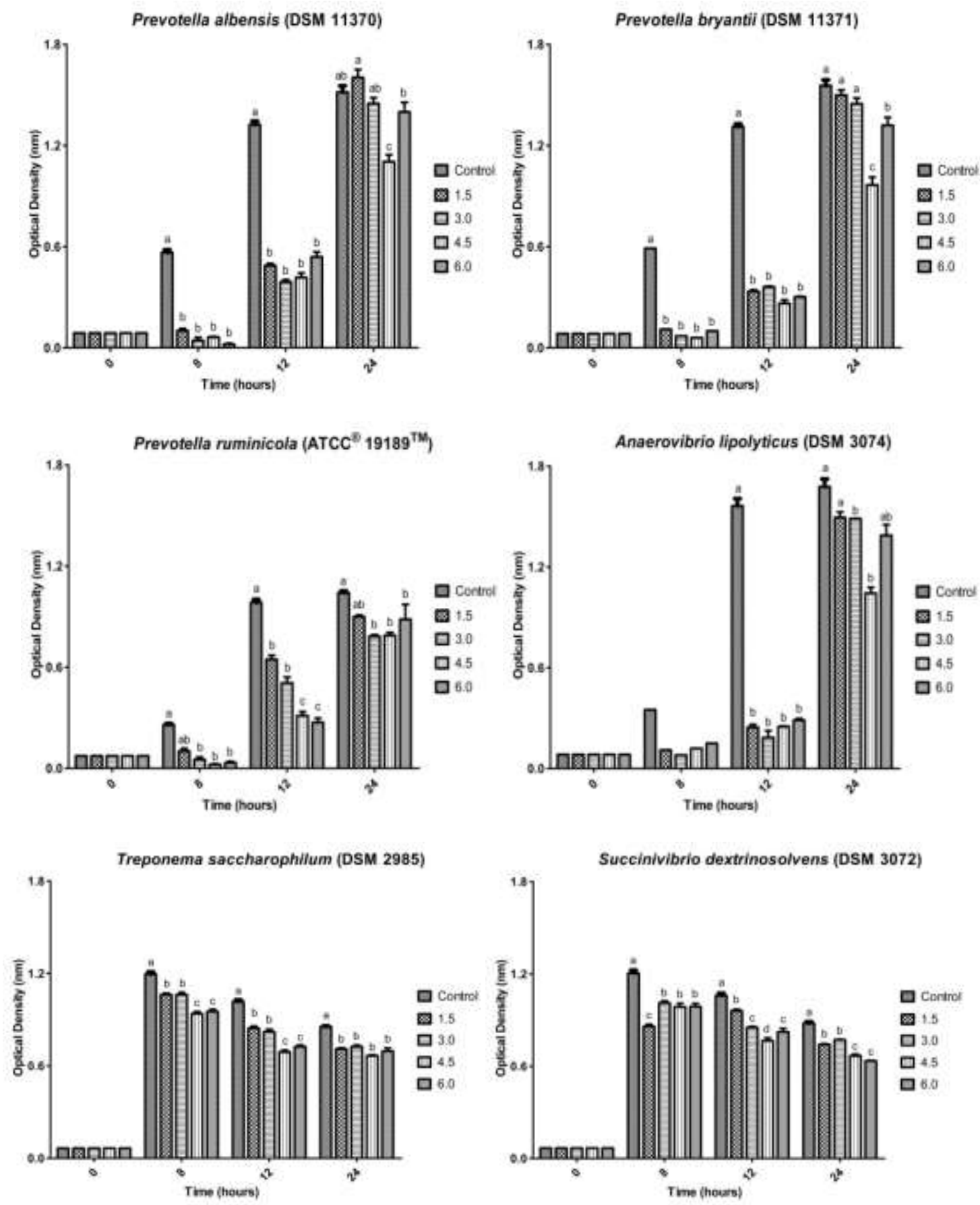

Fonte: Autores. 
Os valores observados entre 12 e 24 horas foram semelhantes ( $>$ > 0,05). Assim, a metodologia utilizada neste experimento foi adequada aos objetivos do trabalho.

As quatro concentrações $(1,5,3,0,4,5$ e $6,0 \mathrm{mg} / \mathrm{mL})$ da mistura de óleos vegetais e essenciais reduziram $(\mathrm{P}<0,001)$ a atividade bacteriana 8 e 12 horas após a incubação da Prevotella albensis, Prevotella bryantii, Prevotella ruminicola e Anaerovibrio lipolyticus (Figura 2). A redução média na atividade de Prevotella albensis foi de 10 vezes às 8 horas 3 vezes às 12 horas após a incubação. Para Prevotella bryantii, a redução na atividade foi de 7 e 3,7 vezes em 8 horas 12 horas após a incubação, respectivamente. Prevotella ruminicola mostrou uma redução da inatividade de 5 vezes em 8 horas 2,3 vezes em 12 horas após a incubação, enquanto para Anaerovibrio lipolyticus a redução foi de 3,2 vezes em 8 horas e 6,5 vezes em 12 horas após a incubação (Figura 2). No entanto, em 24 horas a redução da atividade foi menor para as quatro bactérias (-12\%, -20\%, $25 \%$ e $-22 \%$, respectivamente).

Por outro lado, a mistura de óleos vegetais e essenciais teve menor efeito sobre a atividade de Treponema saccharophilum e Succinivibrio dextrinosolvens em comparação com Prevotella ssp. e Anaerovibrio lipolyticus (Figura 2). A redução da atividade das duas primeiras bactérias foi de $-25 \%$ de 8 a 24 horas. A maior atividade inibitória dessas duas bactérias ocorreu nas doses de 3,0 a 4,5 mg/mL das misturas.

A adição de óleos vegetais e essenciais inibiu a atividade das bactérias gram-negativas nos três momentos estudados (8, 12 e 24 horas). As concentrações mistas tiveram um efeito variável, embora todas as dosagens tenham um efeito positivo em termos de redução da atividade bacteriana. A dose menor $(1,5 \mathrm{mg} / \mathrm{mL})$ reduziu a atividade das seis bactérias estudadas. Da mesma forma, as concentrações de 3,0, 4,5 e 6,0 mg/mL também tiveram um efeito positivo em termos de redução da atividade bacteriana, embora as concentrações de 4,5 e $6 \mathrm{mg} / \mathrm{mL}$ tenham efeito semelhante a 3,0 mg/mL. Assim, a concentração mais efetiva foi $3,0 \mathrm{mg} / \mathrm{mL}$ das misturas estudadas.

\subsection{Bactéria Gram-positiva}

A atividade antibacteriana da Ruminococcus albus e Ruminococcus flavefaciens foi nula nas primeiras oito horas de incubação (Figura 3). Com $12 \mathrm{~h}$ de incubação, essas bactérias apresentaram maior $(\mathrm{P}<0,001)$ atividade antimicrobiana nas concentrações de 3,0 e 4,5 mg/mL (Figura 3) em relação às demais concentrações. O crescimento da Ruminococcus albus e Ruminococcus flavefaciens foi linear a $1,5 \mathrm{mg} / \mathrm{mL}$, mas quadrático a 3,0, 4,5 e 6,0 mg/mL, com o ponto de inflexão ocorrendo em 12 h de incubação. 
Figura 3. Evolução da atividade das bactérias Gram-positivas na mistura de óleos vegetais de caju e mamona e óleos essenciais de cravo, eugenol, timol e vanilina durante 24 horas de incubação.
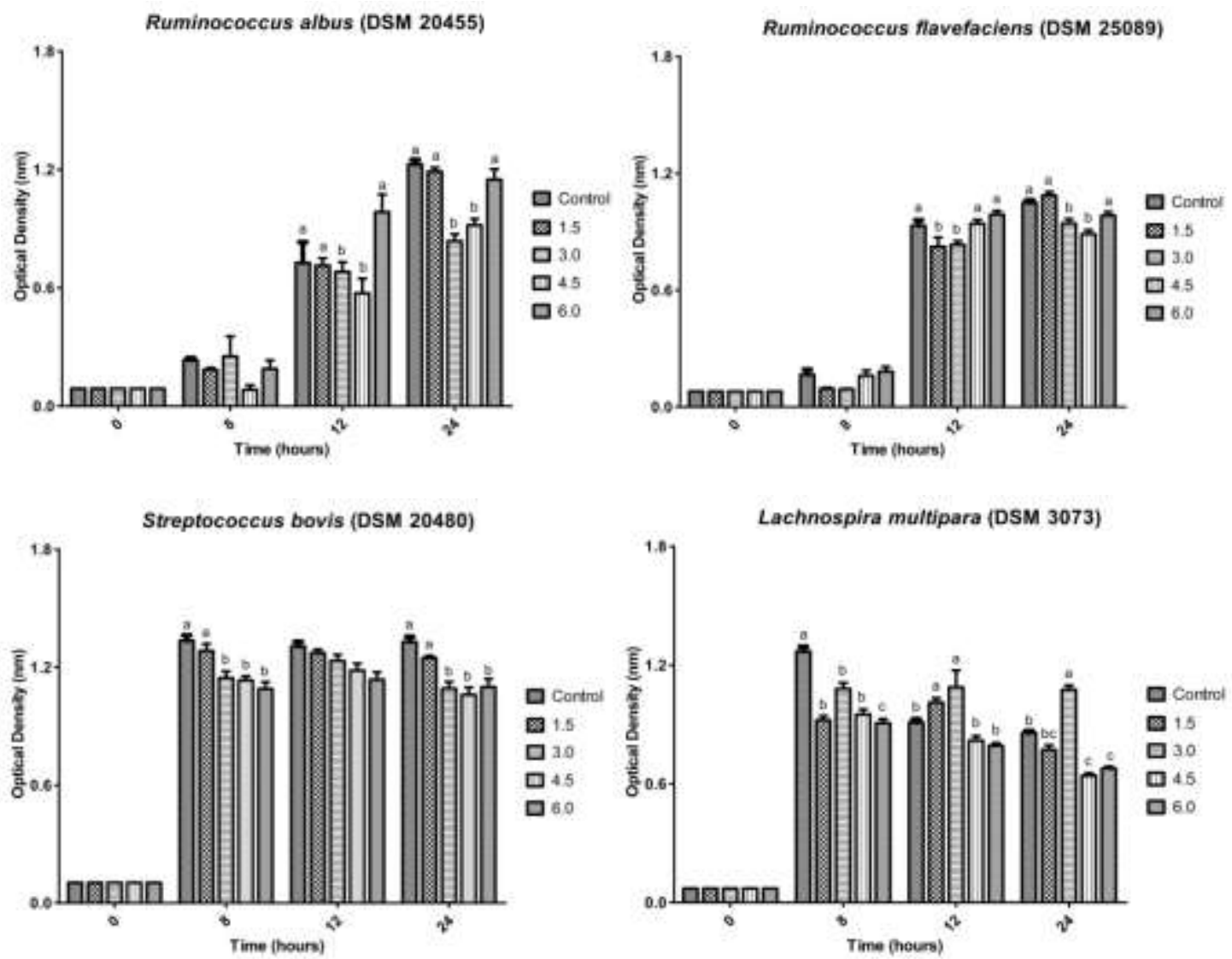

Fonte: Autores.

Streptococcus bovis apresentou menor sensibilidade sobre a atividade antibacteriana das misturas estudadas $(\mathrm{P}>0,05)$. O crescimento desta bactéria não foi alterado pelo tempo de incubação nas concentrações de 1,5 e 6,0 mg/mL (Figura 3). No entanto, nas concentrações de 3,0 e 4,5 mg/mL, o crescimento bacteriano não foi afetado as 8 e 12 horas, mas foi reduzido nas 24 horas $(\mathrm{P}<0,001)$ de incubação. $\mathrm{O}$ crescimento de Lachnospira multipara apresentou maior sensibilidade às combinações estudadas $(\mathrm{P}>0,001)$ nas concentrações de 4,5 e $6,0 \mathrm{mg} / \mathrm{mL}$, principalmente às $24 \mathrm{~h}$ de incubação.

\section{Discussão}

\subsection{Compostos bioativos e capacidade antioxidante}

Os principais fotoquímicos encontrados na combinação (Figura 1) foram característicos dos óleos utilizados na formulação de produtos. O óleo essencial de cravo contém em sua composição eugenol (Biondo et al., 2017; Radünz et al., 2019); o óleo vegetal de caju contém cardol, cardanol e ácidos anacárdicos (Gedam \& Sampathkumaran, 1986) e o óleo de rícino contém ácido ricinoléico (Vignolo \& Naughton, 1991). Esses compostos têm alto potencial antimicrobiano (Nikmaram et al., 2018). Além disso, entre os princípios bioativos presentes no composto micro encapsulado estavam o eugenol e o timol, revelando resultados acurados.

O teor de composto fenólico total na combinação apresentada foi superior aos valores relatados em óleo de cravo (18,56 mg GAE/g) (Babaoglu et al., 2017) e óleo de mamona (variou de 20,2 a 85,6 mg GAE/g) (Akhtar et al., 2018). O alto teor de TPC da mistura de óleos vegetais e óleos essenciais pode ser explicado pelo fato de que a sinergia entre os compostos pode 
aumentar seus efeitos antioxidantes quando são misturados, mesmo em baixas concentrações (Ornaghi et al., 2020; Radünz et al., 2019). Além disso, o conteúdo fenólico total do material ativo pode aumentar com o encapsulamento (Teixeira et al., 2013), como foi visto neste estudo com os ingredientes ativos eugenol, timol e vanilina.

Da mesma forma, os resultados revelaram a possibilidade de eliminação dos radicais livres (DPPH e ABTS) e o poder de redução efetiva do ferro (FRAP) na combinação dos óleos. A propriedade antioxidante da mistura de óleos vegetais e essenciais pode ser atribuída à presença de compostos bioativos. Nesse sentido, a mistura pode ser considerada um bom substituto para as moléculas antioxidantes utilizadas na indústria, como o BHT (2,6-bis (1,1-dimetiletil) -4-metilfenol).

\subsection{Atividade antibacteriana}

Os efeitos in vitro da mistura de óleos vegetais e essenciais foram avaliados contra dez cepas de bactérias ruminais. Os extratos demonstraram amplo poder inibitório para bactérias gram-negativas e gram-positivas. As bactérias selecionadas desempenham importante atividade na nutrição do animal hospedeiro; no entanto, cada um usa substratos específicos para gerar produtos de fermentação no ambiente ruminal.

Prevotella spp. é uma bactéria anaeróbia gram-negativa, caracterizada como uma das bactérias celulolíticas mais importantes do rúmen (Stewart et al., 2012). Essa espécie apresenta grande capacidade de crescimento, principalmente quando estão disponíveis em grandes quantidades de amido, pectina, xilanas e açúcar, levando à produção de lactato, succinato, acetato, fumarato e propionato no rúmen (J B Russell \& Hino, 1985). Acredita-se também que essas bactérias desempenham um papel importante na degradação de proteínas na captação e fermentação de peptídeos (Wallace et al., 2012). No presente estudo, o composto dos óleos vegetais de caju e mamona e óleos essenciais de cravo, eugenol, timol e vanilina reduziram 10,5, 7,0 e 5,0 vezes a atividade de Prevotella albensis, Prevotella bryantii e Prevotella ruminocola após oito horas de incubação. Por outro lado, com 12 horas de incubação, essa redução foi de 3,0, 3,7 e 2,3 vezes para as mesmas três bactérias. Assim, Prevotella spp. a atividade diminuiu com o tempo. Para a bactéria Anaerovibrio lipolyticus, que atua sobre o glicerol e açúcar com succinato, acetato e produção de ácido propionato no rúmen (Stewart et al., 2012), a redução da atividade da mistura foi menor em 8 horas (3,2 vezes) e superior em 12 horas (6,5 vezes) do tempo de incubação em comparação ao seu uso para Prevotella spp.

A ação da mistura de óleos neste estudo foi menor (15\% às oito e 12 horas de incubação) para Succinivibrio dextrinosolvens do que para Prevotella spp. Succinivibrio dextrinosolvens são caracterizados como a bactéria que age sobre a pectina, dextrina e açúcar com succinato, acetato, formato e produção de ácido láctico no rúmen (O’Herrin \& Kenealy, 1993).

O efeito da mistura dos óleos sobre a atividade da bactéria Treponema saccharophilum também foi baixo em oito ($20 \%)$ e 12 (-32\%) horas de tempo de incubação. Esta bactéria gram-negativa usa como substratos ácido poligalacturônico, pectina, amido dextrina, sacarose, maltose, celubiose, D-glicose, D-manose, D-frutose, D-galactose e L-arabinose, gerando como produtos fermentativos fumarato, acetato e produção de ácido láctico no rúmen (Paster \& Canale-Parola, 1985).

Entre as bactérias gram-positivas estudadas, estão as bactérias celulolíticas Ruminococcus albus e Ruminococcus flavefaciens, que utilizam celulose e hemicelulose como substratos. Essas bactérias normalmente produzem ácidos acético e fórmico. Além disso, o ácido succínico é o principal produto da fermentação de Ruminococcus flavefaciens. O etanol é produzido por Ruminococcus albus, mas não por Ruminococcus flavefaciens (Latham \& Wolin, 1977; Russell \& Rychlik, 2001). O crescimento de Ruminococcus albus e Ruminococcus flavefaciens foi nulo nas primeiras oito horas de incubação, mas às 12 horas apresentou maior sensibilidade à mistura de óleos vegetais e essenciais.

No entanto, Streptococcus bovis apresentou menor sensibilidade à mistura utilizada. Seu crescimento só foi afetado às 24 horas de incubação nas concentrações de 3,0 e 4,5 mg/mL. Da mesma forma, o crescimento de Lachnospira multipara apresentou maior sensibilidade à mistura utilizada nas concentrações de 4,5 e 6,0 mg/mL, principalmente às 24 horas de incubação. O Streptococcus bovis é uma das principais bactérias produtoras de ácido lático e, muitas vezes, responsável pelo 
desenvolvimento de acidose ruminal (Enemark, 2008). Também pode produzir acetato, formato e etanol como resultado da fermentação do amido e da glicose (Russell \& Hino, 1985). Por último, Lachnospira multipara fermenta pectina, ácido poligalacturônico, frutose e celubiose. Acetato, formato, etanol e $\mathrm{CO}_{2}$ são os principais produtos finais da fermentação do ácido poligalacturônico e da pectina (Dušková \& Marounek, 2001).

Várias teorias foram propostas para explicar os mecanismos da atividade antibacteriana de compostos de plantas (Gyawali et al., 2015; Olagaray \& Bradford, 2019). De acordo com Davidson \& Naidu (2000), os extratos vegetais podem causar vazamento de conteúdo celular, interferência no transporte ativo ou perda de energia celular na forma de ATP. No entanto, Davidson (1997) observou que a redução do $\mathrm{pH}$ do substrato devido ao aumento da concentração de prótons pode reduzir o $\mathrm{pH}$ celular interno por meio da ionização da molécula de ácido não associada e alterar a permeabilidade da membrana celular. Por outro lado, ácidos orgânicos presentes em extratos vegetais ou óleos essenciais podem inibir a oxidação do NADH. Tal inibição pode eliminar agentes redutores para sistemas de transporte de elétrons (Davidson, 1997). A parte não dissociada de um agente ácido é responsável pela atividade antibacteriana. Assim, a eficiência em um determinado $\mathrm{pH}$ depende principalmente da constante de dissociação do ácido (Hosein et al., 2011). De acordo com Ricke (2003), os ácidos orgânicos podem interferir na permeabilidade da membrana celular. Desse modo, os ácidos orgânicos podem interferir no metabolismo energético, alterando a estrutura da membrana citoplasmática por meio da interação com as proteínas da membrana. Além disso, os óleos essenciais podem produzir danos estruturais e funcionais à membrana celular bacteriana. No mesmo processo, a hidrofobicidade pode estar envolvida na toxicidade (Goñi et al., 2009; Helander et al., 1998). Por outro lado, moléculas antimicrobianas presentes na planta ou em óleos essenciais podem atacar a bicamada fosfolipídica da membrana celular. Tal ataque pode causar danos aos sistemas enzimáticos celulares e comprometer o material genético de uma célula bacteriana, ou formar hidro peroxidase de ácido graxo por meio da oxigenação de ácidos graxos insaturados e morte celular (Burt, 2004). Outra forma da atividade antibacteriana dos flavonoides presentes nas plantas se deve principalmente à capacidade dessas moléculas de penetrar na parede celular das bactérias (Davidson \& Naidu, 2000; Sánchez et al., 2010).

As possíveis teorias sobre o modo de ação relatadas aqui são os principais mecanismos usados para explicar o efeito antibacteriano de extratos de plantas, incluindo óleos essenciais (Gyawali et al., 2015). No entanto, o modo de ação antibacteriano exato dos compostos vegetais contra os microrganismos do rúmen permanece pouco conhecido. Os compostos vegetais podem ter diferentes ações para um grupo específico de microrganismos. Assim, o tipo de atividade observada pode diferir entre as bactérias do rúmen quando desafiadas com o mesmo extrato vegetal (Olagaray \& Bradford, 2019; Patra \& Saxena, 2010).

\section{Conclusão}

Conclui-se que é possível utilizar uma mistura de óleos vegetais de caju e mamona e óleos essenciais de cravo-da-índia, eugenol, timol e vanilina como antimicrobianos naturais. A concentração mais eficaz encontrada foi $3,0 \mathrm{mg} / \mathrm{mL}$ das misturas estudadas. Sua atividade bactericida e antioxidante provavelmente se deve aos seus compostos bioativos.

\section{Agradecimentos}

Este trabalho foi financiado pela Coordenação de Aperfeiçoamento de Pessoal de Nível Superior - CAPES (Brasília, Brasil) para a bolsa Conselho Nacional de Desenvolvimento Científico e Tecnológico - CNPq (Bolsa no 400375 / 2014-1) (Brasília, Brasil) e a Empresa Safeeds Nutrição Animal (Cascavel, Paraná, Brasil). Os autores agradecem a empresa pelo financiamento e disponibilização dos produtos utilizados nesta pesquisa onde foi possível desenvolver este trabalho. A menção de nomes comerciais ou produtos comerciais nesta publicação tem o objetivo exclusivo de fornecer informações específicas e não implica em recomendação ou endosso do Departamento de Zootecnia da Universidade Estadual de Maringá, Paraná, Brasil. 


\section{Referências}

Akhtar, N., Ihsan, U. H., \& Mirza, B. (2018). Phytochemical analysis and comprehensive evaluation of antimicrobial and antioxidant properties of 61 medicinal plant species. Arabian Journal of Chemistry, 11(8), 1223-1235. https://doi.org/10.1016/j.arabjc.2015.01.013.

Babaoglu, H. C., Bayrak, A., Ozdemir, N., \& Ozgun, N. (2017). Encapsulation of clove essential oil in hydroxypropyl beta-cyclodextrin for characterization, controlled release, and antioxidant activity. Journal of Food Processing and Preservation, 41(5), e13202. https://doi.org/10.1111/jfpp.13202.

Benchaar, C., Calsamiglia, S., Chaves, A. V, Fraser, G. R., Colombatto, D., McAllister, T. A., \& Beauchemin, K. A. (2008). A review of plant-derived essential oils in ruminant nutrition and production. Animal Feed Science and Technology, 145(1-4), 209-228. https://doi.org/10.1016/j.anifeedsci.2007.04.014.

Biondo, P. B. F., Carbonera, F., Zawadzki, F., Chiavelli, L. U. R., Pilau, E. J., Prado, I. N., \& Visentainer, .V. (2017). Antioxidant capacity and identification of bioactive compounds by GC-MS of essential oils from spices, herbs and citrus. Current Bioactive Compounds, 13(2), 137-143. https://doi.org/10.2174/1573407212666160614080846.

Burt, S. A. (2004). Essential oils: their antibacterial properties and potential applications in foods—a review. International Journal of Food Microbiology, 94(3), 223-253. https://doi.org/10.1016/j.ijfoodmicro.2004.03.022.

Cruz, O. T. B., Valero, M. V., Zawadzki, F., Rivaroli, D. C., Prado, R. M., Lima, B. S., \& Prado, I. N. (2014). Effect of glycerine and essential oils (anacardium occidentale and ricinus communis) on animal performance, feed efficiency and carcass characteristics of crossbred bulls finished in a feedlot system. Italian Journal of Animal Science, 13(4). https://doi.org/10.4081/ijas.2014.3492.

Davidson, P. M. (1997). Chemical preservatives and natural antimicrobial compounds. In M. P. Doyle, L. R. Beuchat, \& T. J. Montville (Eds.), Food microbiology: fundamentals and frontiers (pp. 520-556). American Society for Microbiology.

Davidson, P. M., \& Naidu, A. S. (2000). Phyto-phenols. In A. S. Naidu (Ed.), Natural Food Antimicrobial Systems (pp. 265-294). CRC - Press. https://doi.org/http://dx.doi.org/10.3168/jds.2007-0347

Deans, S. G., \& Ritchie, G. (1987). Antibacterial properties of plant essential oils. International Journal of Food Microbiology, 5(2), 165-180. https://doi.org/10.1016/0168-1605(87)90034-1

Diggle, P., Diggle, P. J., Heagerty, P., Liang, K.-Y., Heagerty, P. J., \& Zeger, S. (2002). Analysis of longitudinal data. Oxford University Press. https://doi.org/10.2307/2291352.

Dorman, H. J. D., \& Deans, S. G. (2000). Antimicrobial agents from plants: antibacterial activity of plant volatile oils. Journal of Applied Microbiology, 88(2), 308-316. https://doi.org/10.1046/j.1365-2672.2000.00969.x

Dušková, D., \& Marounek, M. (2001). Fermentation of pectin and glucose, and activity of pectin-degrading enzymes in the rumen bacterium Lachnospira multiparus. Letters in Applied Microbiology, 33(2), 159-163. https://doi.org/10.1111/j.1472-765X.2004.01492.x.

Enemark, J. M. D. (2008). The monitoring, prevention and treatment of sub-acute ruminal acidosis (SARA): A review. The Veterinary Journal, 176(1), 32-43. https://doi.org/10.1016/j.tvj1.2007.12.021.

Fugita, C. A., Prado, R. M., Valero, M. V., Bonafé, E. G., Carvalho, C. B., Guerrero, A., Sañundo, C., \& Prado, I. N. (2018). Effect of the inclusion of natural additives on animal performance and meat quality of crossbred bulls (Angus vs. Nellore) finished in feedlot. Animal Production Science, 58(11), $2076-2083$. https://doi.org/10.1071/AN16242.

Gedam, P. H., \& Sampathkumaran, P. S. (1986). Cashew nut shell liquid: Extraction, chemistry and applications. Progress in Organic Coatings, 14(2), 115157. https://doi.org/10.1016/0033-0655(86)80009-7

Goñi, P., López, P., Sánchez, C., Gómez-Lus, R., Becerril, R., \& Nerín, C. (2009). Antimicrobial activity in the vapour phase of a combination of cinnamon and clove essential oils. Food Chemistry, 116(4), 982-989. https://doi.org/http://dx.doi.org/10.1016/j.foodchem.2009.03.058.

Guerrero, A., Rivaroli, D. C., Sañudo, C., Campo, M. M., Valero, M. V, Jorge, A. M., \& Prado, I. N. (2018). Consumer acceptability of beef from two sexes supplemented with essential oil mix. Animal Production Science, 58(9), 1700-1707. https://doi.org/10.1071/AN15306.

Guil-Guerrero, J. L., Ramos, L., Moreno, C., Zúñiga-Paredes, J. C., Carlosama-Yepez, M., \& Ruales, P. (2016). Antimicrobial activity of plant-food by-products: A review focusing on the tropics. Livestock Science, 189, 32-49. https://doi.org/http://dx.doi.org/10.1016/j.livsci.2016.04.021.

Gyawali, R., Hayek, S. A., \& Ibrahim, S. A. (2015). Plant extracts as antimicrobials in food products: Mechanisms of action, extraction methods, and applications. Handbook of Natural Antimicrobials for Food Safety and Quality, 1, 49-68. https://doi.org/http://dx.doi.org/10.1016/B978-1-78242-034-7.00003-7.

Hammer, K. A., Carson, C. F., \& Riley, T. V. (1999). Antimicrobial activity of essential oils and other plant extracts. Journal of Applied Microbiology, 86(6), 985-990.

Helander, I. M., Alakomi, H.-L., Latva-Kala, K., Mattila-Sandholm, T., Pol, I., Smid, E. J., Gorris, L. G. M., \& von Wright, A. (1998). Characterization of the action of selected essential oil components on Gram-negative bacteria. Journal of Agricultural and Food Chemistry, 46(9), 3590-3595.

Hobson, P. N. (1969). Rumen bacteria. Methods in Microbiology, 3B, 133-149. https://doi.org/10.1016/S0580-9517(08)70504-X.

Hosein, A. M., Breidt, F., \& Smith, C. E. (2011). Modeling the effects of sodium chloride, acetic acid, and intracellular pH on survival of Escherichia coli O157: H7. Applied and Environmental Microbiology, 77(3), 889-895. https://doi.org/10.1128/AEM.02136-10.

Hungate, R. E. (1966). The Rumen and its microbes. In The rumen and its microbes (Academic P). https://doi.org/10.1016/B978-1-4832-3308-6.50005-X 
Hyldgaard, M., Mygind, T., \& Meyer, R. L. (2012). Essential oils in food preservation: mode of action, synergies, and interactions with food matrix components. Frontiers in Microbiology, 3(12), 1-24. https://doi.org/10.3389/fmicb.2012.00012.

Jayasena, D. D., \& Jo, C. (2013). Essential oils as potential antimicrobial agents in meat and meat products: A review. Trends in Food Science \& Technology, 34(2), 96-108. https://doi.org/10.1016/j.tifs.2013.09.002.

Kempinski, E. M. B. C., Vital, A. C. P., Monteschio, J. O., Alexandre, S., Nascimento, K. F., Madrona, G. S., Mikcha, J. M. G., \& Prado, I. N. (2017). Development and quality evaluation of infant food with oregano essential oil for children diagnosed with cerebral palsy. LWT - Food Science and Technology, 84, 579-585. https://doi.org/10.1016/j.lwt.2017.06.016.

Latham, M. J., \& Wolin, M. J. (1977). Fermentation of cellulose by Ruminococcus flavefaciens in the presence and absence of Methanobacterium ruminantium. Applied and Environmental Microbiology, 34(3), 297-301. https://doi.org/10.1128/aem.34.3.297-301.1977.

Li, X. M., Tian, S. L., Pang, Z. C., Shi, J. Y., Feng, Z. S., \& Zhang, Y. M. (2009). Extraction of Cuminum cyminum essential oil by combination technology of organic solvent with low boiling point and steam distillation. Food Chemistry, 115(3), 1114-1119. https://doi.org/10.1016/j.foodchem.2008.12.091.

Monteschio, J. O., Souza, K. A., Vital, A. A. C. P., Guerrero, A., Valero, M. V, Kempinski, E. M. B. C., Barcelos, V. C., Nascimento, K. F., \& Prado, I. N. (2017). Clove and rosemary essential oils and encapsuled active principles (eugenol, thymol and vanillin blend) on meat quality of feedlot-finished heifers. Meat Science, 130, 50-57. https://doi.org/10.1016/j.meatsci.2017.04.002.

Monteschio, J. O., Vargas Junior, F. M., Almeida, F. L. A., Pinto, L., Kaneko, I. N., Almeida, A. A., Freitas, L. W., Alves, S. P., Bessa, R. J. B., \& Prado, I. N. (2019). The effect of encapsulated active principles (eugenol, thymol and vanillin) and clove and rosemary essential oils on the structure, collagen content, chemical composition and fatty acid profile of Nellore heifers muscle. Meat Science, 155, 27-35. https://doi.org/10.1016/j.meatsci.2019.04.019.

Nikaido, H. (2003). Molecular basis of bacterial outer membrane permeability revisited. Microbiology and Molecular Biology Reviews, 67(4), 593-656. https://doi.org/http://dx.doi.org/10.1128/MMBR.67.4.593-656.2003.

Nikmaram, N., Budaraju, S., Barba, F. J., Lorenzo, J. M., Cox, R. B., Mallikarjunan, K., \& Roohinejad, S. (2018). Application of plant extracts to improve the shelf-life, nutritional and health-related properties of ready-to-eat meat products. Meat Science, 145, 245-255. https://doi.org/10.1016/j.meatsci.2018.06.031.

O'Herrin, S. M., \& Kenealy, W. R. (1993). Glucose and carbon dioxide metabolism by Succinivibrio dextrinosolvens. Applied and Environmental Microbiology, 59(3), 748-755. https://doi.org/10.1128/aem.59.3.748-755.1993.

Olagaray, K. E., \& Bradford, B. J. (2019). Plant flavonoids to improve productivity of ruminants-A review. Animal Feed Science and Technology, 251, 21-36. https://doi.org/10.1016/j.anifeedsci.2019.02.004.

Ornaghi, M. G., Guerrero, A., Vital, A. C. P., Souza, K. A., Passetti, R. A. C., Mottin, C., Castilho, R. C., Sañudo, C., \& Prado, I. N. (2020). Improvements in the quality of meat from beef cattle fed natural additives. Meat Science, 163, 1-9. https://doi.org/10.1016/j.meatsci.2020.108059.

Ornaghi, M. G., Passetti, R. A. C., Torrecilhas, J. A., Mottin, C., Vital, A. C. P., Guerrero, A., Sañudo, C., Campo, M. M., \& Prado, I. N. (2017). Essential oils in the diet of young bulls: Effect on animal performance, digestibility, temperament, feeding behaviour and carcass characteristics. Animal Feed Science and Technology, 234, 274-283. https://doi.org/10.1016/j.anifeedsci.2017.10.008.

Paster, B. J., \& Canale-Parola, E. (1985). Treponema saccharophilum sp. nov., a large pectinolytic spirochete from the bovine rumen. Applied and Environmental Microbiology, 50(2), 212-219. https://doi.org/10.1128/aem.50.2.212-219.1985.

Patra, A. K., \& Saxena, J. (2009). Dietary phytochemicals as rumen modifiers: a review of the effects on microbial populations. Antonie Van Leeuwenhoek, 96(4), 363-375.

Patra, A. K., \& Saxena, J. (2010). A new perspective on the use of plant secondary metabolites to inhibit methanogenesis in the rumen. Phytochemistry, 71(1112), 1198-1222. https://doi.org/10.1016/j.phytochem.2010.05.010.

Pereira A.S. et al. (2018). Metodologia da pesquisa científica. UFSM. https://repositorio.ufsm.br/bitstream/handle/1/15824/Lic_Computacao_MetodologiaPesquisa-Cientifica.pdf?sequence $=1$

Radünz, M., Trindade, M. L. M., Camargo, T. M., Radünz, A. L., Borges, C. D., Gandra, E. A., \& Helbig, E. (2019). Antimicrobial and antioxidant activity of unencapsulated and encapsulated clove (Syzygium aromaticum, L.) essential oil. Food Chemistry, 276, 180-186. https://doi.org/10.1016/j.foodchem.2018.09.173.

Re, R., Pellegrini, N., Proteggente, A., Pannala, A., Yang, M., \& Rice-Evans, C. (1999). Antioxidant activity applying an improved ABTS radical cation decolorization assay. Free Radical Biology and Medicine, 26(9), 1231-1237.

Ricke, S. C. (2003). Perspectives on the use of organic acids and short chain fatty acids as antimicrobials. Poultry Science, 82(4), 632-639. https://doi.org/10.1093/ps/82.4.632.

Rivaroli, D. C., Guerrero, A., Valero, M. V., Zawadzki, F., Eiras, C. E., Campo, M. D. M., Sañudo, C., Jorge, A. M., \& Prado, I. N. (2016). Effect of essential oils on meat and fat qualities of crossbred young bulls finished in feedlots. Meat Science, 121, 278-284. https://doi.org/10.1016/j.meatsci.2016.06.017.

Russell, J B, \& Hino, T. (1985). Regulation of lactate production in Streptococcus bovis: a spiraling effect that contributes to rumen acidosis. Journal of Dairy Science, 68(7), 1712-1721. https://doi.org/10.3168/jds.S0022-0302(85)81017-1.

Russell, J B, \& Strobel, H. J. (1989). Effect of ionophores on ruminal fermentation. Applied and Environmental Microbiology, 55(1), 1-6. https://doi.org/10.1128/aem.55.1.1-6.1989.

Russell, James B, \& Rychlik, J. L. (2001). Factors that alter rumen microbial ecology. Science, 292(5519), 1119-1122. https://doi.org/http://doi.org/10.1126/science.1058830. 
Saavedra, M. J., Borges, A., Dias, C., Aires, A., Bennett, R. N., Rosa, E. S., \& Simões, M. (2010). Antimicrobial activity of phenolics and glucosinolate hydrolysis products and their synergy with streptomycin against pathogenic bacteria. Medicinal Chemistry, 6(3), 174-183. https://doi.org/10.2174/1573406411006030174.

Sánchez, E., García, S., \& Heredia, N. (2010). Extracts of edible and medicinal plants damage membranes of Vibrio cholerae. Applied and Environmental Microbiology, 76(20), 6888-6894. https://doi.org/10.1128/AEM.03052-09.

Sary, C., Carbonera, F., Silva, M. C. D., Oliveira, M., Lewandowski, V., Todesco, H., Visentainer, J. V., Prado, I. N., \& Ribeiro, R. P. (2019). Effect of clove (Eugenia caryophyllus) and cinnamon (Cinnamomum zeylanicum) essential oils in Nile tilapia diets on performance, antioxidant power and lipid oxidation in fillets. Aquaculture Research, 50(2). https://doi.org/10.1111/are.13944.

Schäberle, T. F., \& Hack, I. M. (2014). Overcoming the current deadlock in antibiotic research. Trends in Microbiology, 22(4), 165-167. https://doi.org/10.1016/j.tim.2013.12.007.

Singleton, V. L., \& Rossi, J. A. (1965). Colorimetry of total phenolics with phosphomolybdic-phosphotungstic acid reagents. American Journal of Enology and Viticulture, 16(3), 144-158.

Souza, K. A., Monteschio, J. O., Mottin, C., Ramos, T. R., Pinto, L. A. M., Eiras, C. E., Guerrero, A., \& Prado, I. N. (2019). Effects of diet supplementation with clove and rosemary essential oils and protected oils (eugenol, thymol and vanillin) on animal performance, carcass characteristics, digestibility, and ingestive behavior activities for Nellore heifers finished in feedl. Livestock Science, 220, 190-195. https://doi.org/10.1016/j.livsci.2018.12.026.

Stewart, C. S., Flint, H. J., \& Bryant, M. P. (2012). The rumen bacteria. In P. N. Hobson \& C. S. Stewart (Eds.), Rumen microbial ecosystem (2nd ed., Vol. 1, pp. 10-72). Blackie Academic \& Professional.

Teixeira, B., Marques, A., Ramos, C., Neng, N. R., Nogueira, J. M. F., Saraiva, J. A., \& Nunes, M. L. (2013). Chemical composition and antibacterial and antioxidant properties of commercial essential oils. Industrial Crops and Products, 43, 587-595. https://doi.org/10.1016/j.indcrop.2012.07.069.

Valero, M. V, Farias, M. S., Zawadzki, F., Prado, R. M., Fugita, C. A., Rivaroli, D. C., Ornaghi, M. G., \& Prado, I. N. (2016). Feeding propolis or essential oils (cashew and castor) to bulls: performance, digestibility, and blood cell counts. Revista Colombiana de Ciencias Pecuarias, $29(1), 33-42$.

Vignolo, R., \& Naughton, F. (1991). Castor: a new sense of direction. Inform, 2(8), 692-699.

Vital, A. C. P., Guerrero, A., Kempinski, E. M. B. C., Monteschio, J. O., Sary, C., Ramos, T. R. R., Campo, M., \& Prado, I. N. (2018). Consumer profile and acceptability of cooked beef steks with edible and active coating containing oregano and rosemary essential oils. Meat Science, 143, 153-158. https://doi.org/10.1016/j.meatsci.2018.04.035.

Vital, A. C. P., Guerrero, A., Monteschio, J. D. O., Valero, M. V., Carvalho, C. B., Abreu Filho, B. A., Madrona, G. S., \& Prado, I. N. (2016). Effect of edible and active coating (with rosemary and oregano essential oils) on beef characteristics and consumer acceptability. PLoS ONE, 11(8). https://doi.org/10.1371/journal.pone.0160535.

Wallace, R. J., Onoder, R., \& Cotta, M. A. (2012). Metabolism of nitrogen-containing compounds. In P. N. Hobson \& C. S. Stewart (Eds.), Rumen microbial ecosystem (2nd ed., Vol. 1, pp. 283-328). Blackie Academic \& Professional.

Zhu, Q. Y., Hackman, R. M., Ensunsa, J. L., Holt, R. R., \& Keen, C. L. (2002). Antioxidative activities of oolong tea. Journal of Agricultural and Food Chemistry, 50(23), 6929-6934. https://doi.org/10.1021/jf0206163.

Zotti, C. A., Silva, A. P., Carvalho, R., Marino, C. T., Rodrigues, P. H. M., Silva, L. F. P., McAllister, T. A., \& Leme, P. R. (2017). Monensin and a blend of castor oil and cashew nut shell liquid used in a high-concentrate diet abruptly fed to Nellore cattle. Journal of Animal Science, 95(9), 4124-4138. https://doi.org/10.2527/jas2017.1580.

Zuzarte, M., Gonçalves, M. J., Cavaleiro, C., Cruz, M. T., Benzarti, A., Marongiu, B., Maxia, A., Piras, A., \& Salgueiro, L. (2013). Antifungal and antiinflammatory potential of Lavandula stoechas and Thymus herba-barona essential oils. Industrial Crops and Products, 44(0), 97-103. https://doi.org/10.1016/j.indcrop.2012.11.002. 